coma requires specific actions to be taken which can not depend on whim but are the same for all times and all places. Yet dismissing postmodernism simply because the technology of medicine is universally applicable is too easy for at least two reasons.

Firstly, until now medicine has been glued together by a set of myths that everyone subscribed to: doctors battled against death and disease, we lived under the one true church of the NHS, and Science lit the way to a world of health for all. Today these comforting narratives are less believable. In a very postmodern way, doctors have to juggle competing ways of seeing the same situation. Clinical reality as perceived by clinicians has to be reconciled with patients' beliefs, "resources" have to balanced against individual patient need, and ethical dilemmas spring hydra-headed from medical advance.

Secondly, the anything goes nature of postmodernism is being radically reinforced by the anything is possible nature of technology. It is not only Marxism and the Enlightenment which are dead; utterly unquestioned biological givens are disintegrating all around us: the stability of the climate, the immutability of species, a life span of three score years and ten, the unchangeable genetic make up of ones' unborn children. "Facts of life" melt away, and our collective sense of bewilderment and wide eyed possibility rises.

As technology expands the bounds of what it is possible to do, it seems inevitable that clinicians will become agents of the postmodernism that they have so far ignored. Medical technologies will increasingly be used for non-therapeutic ends. ${ }^{4}$ Recreational drug use may come to be matched by "recreational surgery"-perhaps an expanded plastic surgery or the augmentation of natural capabilities via mechanical prostheses. At some point in this process medicine's modernist centre fails. Doctors will no longer be able to comfort themselves with the hard edged certainty that their work is "fighting disease." Instead they will have become purveyors of choice-or agents of control-within the plastic limits of the flesh.

Postmodernism may seem altogether too hip and slippery for the staid old world of medicine. Yet we are no more immune than the Amish or the makers of the Betamax to the pluralistic, fragmented webs of power and knowledge that our accelerating technoculture is creating. It is the nature of postmodern societies that no new over arching visions are possible. The language is no sooner minted than it fractures into different perspectives, and simultaneously we sense, somewhere in our bones, that it is certainty itself that has ended.

PAUL HODGKIN

General practice adviser

The FACTS Project,

Sheffield School for Health and Related Research,

Regents Court,

30 Regent Street,

Sheffield S1 4DA

1 Neil Smith quoted in Parker M. Post-modern organisations or postmodern organisation theory? Organizational Studies 1992;13:1-17.

2 Appignanesi R, Garratt C. Postmodernism for beginners. London: Icon Books, 1995.

3 Charlton B. Medicine and postmodernity. f Roy Soc Med 1993; 86:497-9.

4 Dery M. Escape velocity. Cyberculture at the end of the century.London: Hodder \& Stoughton, 1996: 249 .

\title{
The power of placebo
}

\author{
Let's use it to help as much as possible
}

Links are revealed this week between the colour of a pill, its name, and its pharmacological action (pp 1624, 1627). ${ }^{12}$ This news will come as no surprise to many. Pink pills and tonics were the mainstay of many physicians-perhaps their main resource-before the era of antibiotics. But what are the active ingredients of the placebo effect and how can we make the best use of it?

Many non-specific concomitants of treatments help to determine the direction and size of the placebo effect. These can be placed on a continuum ranging from the tangible to the intangible. ${ }^{3}$ The form of medications, touch, words, gestures, and the ambience of the consultation can all play a part in conveying a doctor's confidence in a treatment, empathy with the patient, and professional status. ${ }^{4-6}$ Non-specific aspects of the remedy itself can also have a powerful influence; the more invasive it is, or the more actively it involves the patient, the larger the placebo effect. ${ }^{78}$

All of these determinants relate to the fact that the mind can influence the body. This notion has always been accepted in good medical practice, and much evidence exists to show that the effect is clinically relevant. It would be desirable to know how the use of placebo effects differs between mainstream and complementary practices. Preliminary survey data suggest that patients who use both forms of treatments are more impressed by the therapeutic encounter in complementary rather than mainstream medicine (Ernst E, unpublished data).

We know far too little about the importance of the non-specific effects and their interactions with specific treatments. We know that patients who receive a reasonable explanation from a member of the surgical team about an intervention will fare better than those who get no such information. ${ }^{9}$ One can argue about whether this information is part of the treatment or whether it is a non-specific effect. But the effect itself is important, must be studied, and should be optimised.

Systematic research on placebo effects has been neglected for the past 30 years; placebos have been used largely as a tool for reducing bias in clinical trials. ${ }^{10}$ Nurses routinely apply placebos in clinical practice, ${ }^{11}$ but most doctors still feel uncomfortable about the subject because using a placebo seems to imply deception. ${ }^{12}$

A multidisciplinary research programme is needed to define and examine the most important questions about non-specific factors and their effects. Further studies on the "best" colours and other properties of tablets, capsules, and patches would be interesting but do not perhaps offer much scope for improved effectiveness over the many purposefully distinctive products now available. The issues are complex. For example, heart shaped patches worn over the heart releasing transdermal glyceryl trinitrate are probably marvellous placebos as well as having a pharmacological effect, but they cost much more than other more versatile forms of the drug. Is the balance between cost-benefit acceptable?

Holm and Evans ( $p$ 1627) raise the possibility that the names of drugs could influence their actions. ${ }^{2}$ This requires experimental investigation. An effort to control names seems necessary on ethical grounds to prevent implied claims that are unjustified or exaggerated.The five yearly review of product licences by Britain's Medicines Control Agency could be used 
to give an expiry date to the worst names, and the licensing rules could be used now to prevent names that make unjustifiable claims. Perhaps there should be an international prize each year to be awarded for the most honest, optimistic, and pleasant product name, and an award for the worst name of the year.

Meanwhile, all doctors should be encouraged to look at their own practice, to examine the non-specific ingredients that they use daily, and those that they do not use. Giving greater attention in daily practice to "adjuvants" (specific as well as non-specific) could considerably increase effectiveness and efficiency-for example, by saying more useful things to patients in better ways. Methods will be needed for implement-

1 de Craen AJM, Roos PJ, de Vries AL, Kleiinen J. Effect of colour of drugs: systematic review of perceived effect of drugs and their effectiveness. $B M Y$ 1996;313:1624-6.

Holm S, Evans M. Product names, proper claims? More ethical issues in the marketing of drugs. BMF 1996;313:1627-9.

3 Chaput de Saintonge DM, Herxheimer A. Harnessing placebo effects in health care. Lancet 1994;344:995-8.

Shapiro AK, Wilensky H, Struening EL. Study of the placebo effect with a placebo test. Compr Psychiatry 1968;9:118-37.

Uhlenhuth EH, Canter A, Neustadt JO, Payson HE. The symptomatic relief of anxiety with meprobamate, phenobarbital and placebo. Am f Psychiatry 1959;115:905-10.

Thomas KB. General practice consultations: is there any point in being positive? $B M 9$ $1987 ; 294: 1200-2$ ing such approaches. Until they are available, good common sense and old fashioned bedside manners might already take us far-as they say, when all else fails talk to your patient.

E ERNST

Professor

Department of Complementary Medicine,

Postgraduate Medical School

University of Exeter,

Exeter EX2 4NT

A HERXHEIMER

9 Park Crescent,

Emeritus fellow, UK Cochrane Centre,

London N3 2NI
Luparello T, Leist $\mathbf{N}$, Lourie $\mathrm{CH}$, Sweet $\mathrm{P}$. The interaction of psychologic stimuli and pharma- cologic agents on airway reactivity in asthmatic subjects. Psychosom Med 1970;32:509-13. Saradeth T, Resch KI, Ernst E. Placebo for varicose veins-don't eat it, rub it! Phlebology 1994;9:63-6.
Dahan R, Caulin C, Figea L, Kanis JA, Caulin F, Segretaa JM. Does informed consent influ- ence therapeutic outcome? $B M F$ 1986;293:363-4.
11 Ernst E, Abbot NC. Placebos in clinical practice, results of a survey of nurses. Perfusion 1997 (in press).
12 Wall PD. The placebo effect, an unpopular topic. Pain 1992;51:1-3.

\section{The magic of seven}

\section{Signifies creation, the sum of the spiritual three and the material four}

The seven ages of man, the seven seas, the seven deadly sins (p 1592), the seven league boot, seventh heaven, the seven wonders of the world, the seven pillars of wisdom, Snow White and the seven dwarves, 7-up.... There are an awful lot of sevens around. Numerologists see seven as the sum of the spiritual three and the material four, signifying creation. The Old Testament tells us that the world was created in seven days. The seventh generation after Adam produced Lamech, who lived for 777 years and was to be avenged 77 fold. Psalm 90 sets the human life span at seven decades. Solomon's temple has seven steps, and Noah's dove returns after seven days.

In the Hippocratic tradition the number seven governs the ailments of the body. In Germany it was believed that people would not catch swine fever if they spent seven days drinking and bathing in water containing asphodel. A Jewish cure for fever involved taking "seven prickles from seven palmtrees, seven chips from seven beams, seven nails from seven doors," and so on up to "seven hairs from the beard of an old dog." And in this issue of the $B M F$ a long but neglected tradition alleging seven year cycles in human development is vindicated in Jos Verhulst and Patrick Onghena's finding of a circaseptennial (roughly seven year) rhythm in the growth of male human ears (p 1597). ${ }^{2}$

In Iranian folklore the cat has seven, not nine, lives and carries her kittens seven times to seven different places. "'To do the work of seven mullahs" means to accomplish absolutely nothing. In ancient India the most important numbers were three and seven. The ancient Indian text Rigveda talks of seven stars and seven streams of soma (the drink of the gods). ${ }^{1}$ Indra, the rain god, is "the seven-slayer," the ocean has seven depths, and there are seven concentric continents. The sacred cow has 21 names-three times seven.

In ancient Greece, seven was associated with Athena, the virgin goddess, because it is neither producing nor producedthat is, it has no multiple in the first decade (1-10) and also no divisor (other than 1). The first property has little mathematical importance, but the second tells us that seven is a prime number-having no divisors other than itself and one. It is the second Mersenne prime- one less than a power of two. ${ }^{3}$

Seven numbers suffice to colour every map on a torus-a surface shaped like a doughnut with a central hole-so that no two adjacent regions have the same colour. The smallest regular polygon that cannot be constructed using ruler and compasses is the heptagon, with seven sides. All sufficiently large whole numbers are the sum of seven perfect cubes. And it you want to get more esoteric, the unit sphere in a multidimensional space has the greatest surface area when the space has dimension seven.

Seven is an astronomical number. The week has seven days because successive phases of the moon occur roughly seven days apart. Other astronomical sevens include the "seven sisters," the stars of the constellation of the Pleiades, and-in ancient times only-the seven planets: Sun, Moon, Mercury, Venus, Mars, Jupiter, Saturn. In Douglas Adams's The Hitch Hiker's Guide to the Galaxy the answer to the "Great Question of Life, the Universe, and Everything," is 42 (six times seven). ${ }^{4}$ In November 1996 the Independent reported the latest measurements of Hubble's constant-a fundamental physical quantity that determines the rate of growth of our expanding universe." "Dr Richard Saunders," the newspaper wrote, "sounded a trifle abashed by the result. "We have taken two measurements for the constant, and the average of them is, well, it's 42."”

IAN STEWART Professor

Mathematics Institute,

University of Warwick,

Coventry CV4 7AL

1 Schimmel A. The mystery of numbers. Oxford:Oxford University Press, 1993. 2 Verhulst J, Onghena P. Circaseptennial rhythm in ear growth. BMY 1993;313:1597-8.

3 Wells D. The Penguin dictionary of curious and interesting numbers. Harmondsworth, Penguin, 1986.

Adams D. The hitch hiker's guide to the galaxy. London: Pan Books, 1979.

5 Arthur C. Yes, the answer to the Universe really is 42. The Independent, 1996.Nov 8:1. 